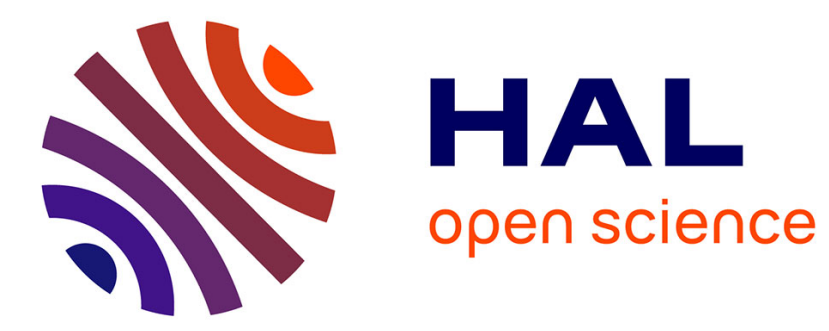

\title{
Biosynthesis of azaphilones: a review
}

Coralie Pavesi, Victor Flon, Stéphane Mann, Stéphane Leleu, Soizic Prado, Xavier Franck

\section{To cite this version:}

Coralie Pavesi, Victor Flon, Stéphane Mann, Stéphane Leleu, Soizic Prado, et al.. Biosynthesis of azaphilones: a review. Natural Product Reports, 2021, 10.1039/D0NP00080A . hal-03132866

\section{HAL Id: hal-03132866}

\section{https://hal-normandie-univ.archives-ouvertes.fr/hal-03132866}

Submitted on 5 Feb 2021

HAL is a multi-disciplinary open access archive for the deposit and dissemination of scientific research documents, whether they are published or not. The documents may come from teaching and research institutions in France or abroad, or from public or private research centers.
L'archive ouverte pluridisciplinaire HAL, est destinée au dépôt et à la diffusion de documents scientifiques de niveau recherche, publiés ou non, émanant des établissements d'enseignement et de recherche français ou étrangers, des laboratoires publics ou privés. 


\title{
Biosynthesis of azaphilones: a review
}

Received 00th January 20xx, Accepted 00th January 20xx DOI: $10.1039 / \times 0 \times x 00000 x$

\author{
Coralie Pavesi $^{\mathrm{at}}{ }^{+}$Victor Flon $^{\mathrm{b}+}$, Stéphane Mann ${ }^{\mathrm{a}}$, Stéphane Leleu ${ }^{\mathrm{b}}$, Soizic Prado*a, \\ Xavier Franck*b
}

\begin{abstract}
Azaphilones are fungal polyketide pigments bearing a highly oxygenated pyranoquinone bicyclic core which receive an increasing great deal of research interest for their applications on agroalimentary, dyeing, cosmetic, printing and pharmacy industries. Their biosynthetic pathways are not fully elucidated but thanks to recent genomic approaches combined to the increasing genome sequencing of fungi some of them have been recently unveiled. Here is the first review on the biosynthesis of azaphilonoids adressed from a genomic point of view.
\end{abstract}

\section{Introduction}

Azaphilone compounds are fungal polyketides produced by numerous species of ascomyceteous and basidiomyceteous fungi. Besides their well-known pigment functions, azaphilones exhibit a wide range of potent biological activities. Many of these activities are attributed to their affinity for the amino groups present in proteins or nucleic acids. In view of these promising biological activities, pigment functions and interesting structural features, azaphilones have increasingly received a great deal of research interest. Earlier studies of azaphilone biosynthesis, using isotope labeled substrates, allowed an outline of the pathway to be proposed. Subsequently, genomic approaches combined to the increasing genome sequencing of fungi allowed discovering the biosynthetic gene clusters (BGCs) involved in the azaphilones biosynthesis, and paved the way to deciphering it. In this highlight, we thus review the recent findings regarding the biosynthetic gene clusters involved in the production of azaphilones.

\section{Results}

Azaphilones are produced by 61 genera of fungi belonging to Annulohypoxylon spp., Ascochyta spp., Aspergillus spp., Bartalinia $s p$. ., Beauveria sp., Biscogniauxia sp., Bulgaria spp., Cephalotheca $s p$. ., Cercosporella sp., Chaetomium spp., Cladosporium sp., Cochliobolus spp., Colletotrichum spp., Coniella sp., Creosphaeria $s p .$, Curvularia sp., Cyathus spp., Cylindrocarpon spp., Cytospora sp., Daldinia spp., Delitschia spp., Diaporthe sp., Dothideomycete sp.,

\footnotetext{
a. Unité Molécules de Communication et Adaptation des Micro-organismes (UMR 7245), Sorbonne Université, Muséum national d'Histoire naturelle, CNRS, CP 54 57 rue Cuvier, 75005 Paris, France. E-mail : soizic.prado@mnhn.fr

${ }^{b .}$ Normandie Univ, CNRS, UNIROUEN, INSA Rouen, COBRA (UMR 6014 \& FR 3038), 76000 Rouen, France.E-mail : xavier.franck@insa-rouen.fr

† These authors contributed equally to this work

Electronic Supplementary Information (ESI) available: [details of any supplementary information available should be included here]. See

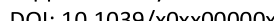

Emericella spp., Entonaema sp., Epicoccum nigrum, Eupenicillium sp., Fusarium spp., Fusidium sp., Glaziella sp., Helotialean spp., Hypocrella sp., Hypoxylon spp., Leptosphaeria spp., Microdochium sp., Monascus spp., Montagnulaceae sp., Mycoleptodiscus sp., Nemania sp., Nidularia sp., Nigrospora sp., Penicillium spp., Pestalotiopsis sp., Peyronellaea sp., Phialophora sp., Phomopsis spp., Pithomyces spp., Pleosporales sp. Pleurostomophora sp., Pochonia sp., Podospora sp., Pseudohalonectria spp., Sepedonium $s p$., Stachybotrys sp., Talaromyces spp., Thielavia sp., Trichocladium $s p$. Trichoderma sp., Trichopezizella $s p$., Xylariales $s p$. and Zopfiella sp.. From all those genera 677 azaphilones have already been described and a substantial updated azaphilone database is provided in Table S1 describing the name of the azaphilone along with its structural chemical family, the producing strains, its molecular formula and neutral mass. This work will prove to be of significance for fungal dereplication processes in the azaphilone series.

This review is intended to continue the coverage of the literature previously reviewed in this journal by Chen W. (1) and recently by Chen C (2). It will mainly focus on the recent biosynthetic studies of azaphilones for which the biosynthetic genes/enzymes have been identified. Five main biosynthetic pathways have been described among the 61 genera of fungi, so far: The Monascus azaphilone pathway (MAzPs), the Aspergillus azaphilone pathway, the citrinin pathway, the Chaetomium/cochliodone pathway as well as the Hypoxylon pathway.

The five described azaphilone biosynthetic pathways share a common beginning. Either a non-reducing PKS (nrPKS), or a highlyreducing (hrPKS) and a nrPKS, build a common orcinaldehyde intermediate which can be either tailored by enzymes towards the citrinin pathway or hydroxylated by a monooxygenase to produce a common pyranoquinone core tailored to the MazPs, Aspergillus azaphilone pathway, Chaetomium/cochliodone or Hypoxylon pathway (see Figure 1). 


\section{ARTICLE}

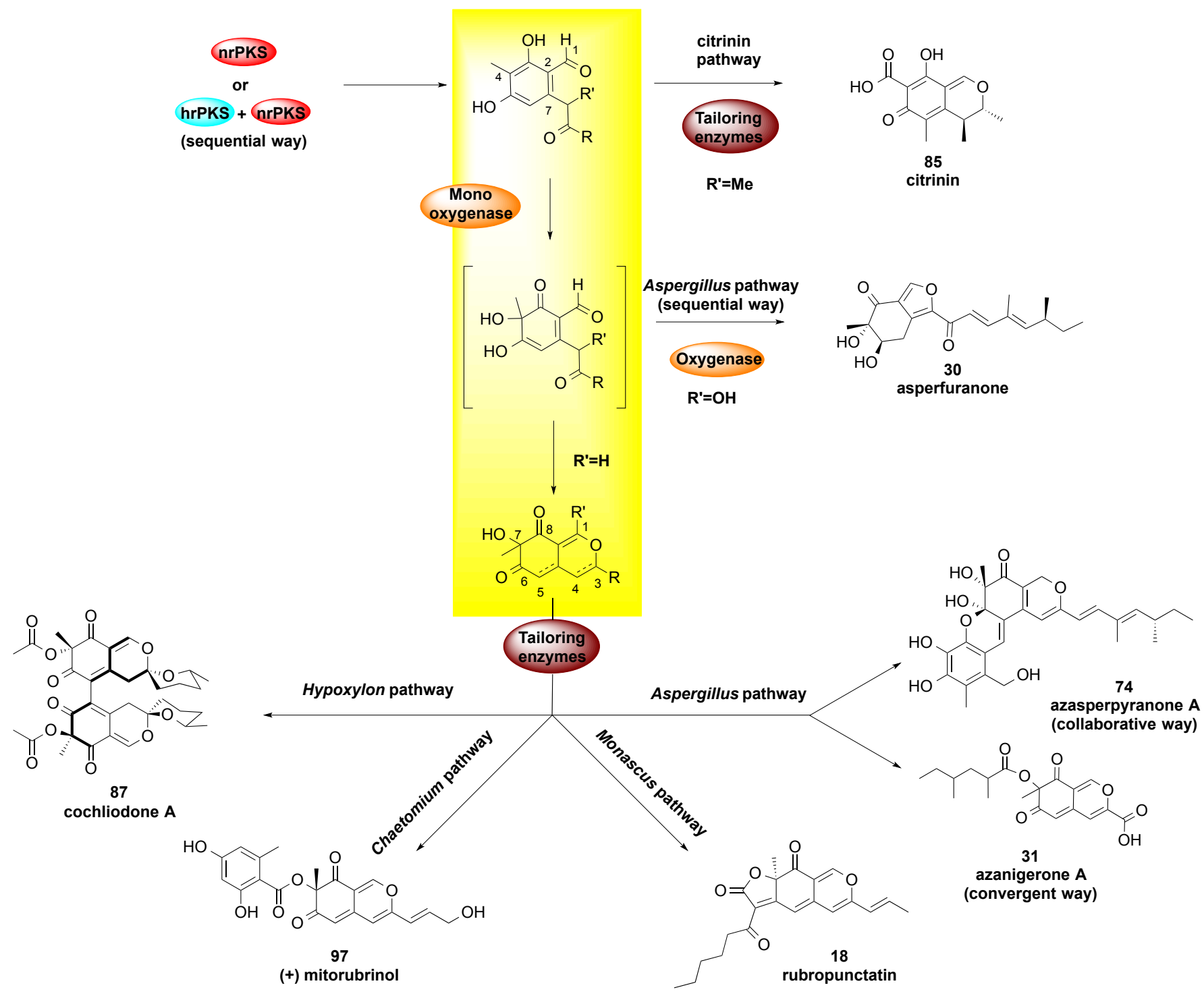

Figure 1 Described azaphilones biosynthetic pathways

\section{The Monascus azaphilone pathway}

Seven MAzPS biosynthetic gene clusters were described from the Monascus genus: $M$. purpureus M3103 (3), M. purpureus NRRL 1596, M. purpureus YY-1, M. pilosus, M. ruber M7,(4) M. purpureus KACC42430 and M. ruber NRRL 1597 and four on the Talaromyces genera: Talaromyces aculeatus ATCC10409, T. atroroseus IBT11181, T. marneffei ATCC18224 and T. stipitatus ATCC10500 (1). The comparison of the clusters revealed that the genes are conserved but the physical order of the genes is different between Monascus and Talaromyces. Thanks to the efforts of few teams (4-14) using a combination of gene knockouts, heterologous expression and in vitro reconstitution of selected reactions, knowledge concerning the biosynthesis pathway of Monascus azaphilone pigments was considerably improved (Figure 2).

The MonAzPs biosynthesis is initiated by a nrPKS (MrPigA in $M$. ruber or MpPKS5 in $M$. purpureus) featuring eight domains as follow: a starting unit acyltransferase (SAT), a keto-synthase (KS), an acyltransferase (AT), a product template (PT), a C-methyltransferase $(\mathrm{MT})$, two acyl carrier proteins (ACP), and a reductive release domain (R). Briefly, according to Chen et al. (4) the SAT domain of MrPigA selects an acetyl-CoA starter unit which is extended five 
times with malonyl-CoA in successive decarboxylative Claisen condensation cycles thanks to KS, AT and ACP domains. Then, the methyltransferase (MT) domain of MrPigA conducts a single Cmethylation at C-4, most likely at the pentaketide stage. The reactive hexaketide chain then undergoes a product template (PT) domain-mediated C-2 to C-7 aldol cyclization to afford the aromatic ring followed by reductive release catalysed by the $\mathrm{R}$ domain of MrPigA to afford the putative benzaldehyde intermediate 2. A deduced serine hydrolase MrPigG may help the release of the reactive intermediate 2 from MrPigA (4).

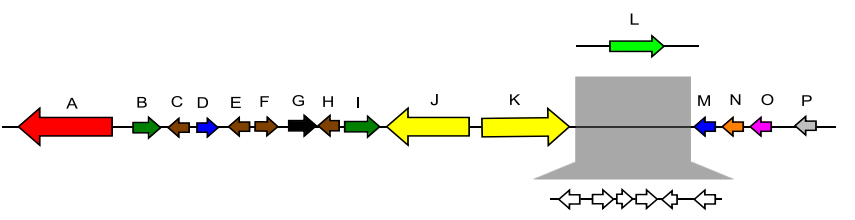

M. purpureus NRRL1596, M. purpureus YY-1, M. ruber M7, M. pilosus, M. ruber NRRL 1597

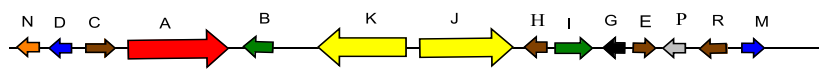

T. marneffei ATCC18224, T. atroroseus IBT11181, T. stipitatus ATCC10500, T. aculeatus ATCC10409

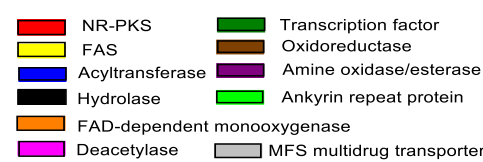

Figure 2 MonAzPs biosynthetic gene clusters for Monascus and Talaromyces genera (1)

It should be noted that according to Balakrishnan et al. MrPigA contained only one acyl-carrier protein while Chen et al. described two ACP (5). To the best of our knowledge, the importance or interest of the second ACP in MrPigA has yet to be discussed.

The MrPigC therefore intercepts the reactive benzaldehyde $\mathbf{2}$ to reduce the $\omega-1$ carbonyl into the corresponding alcohol 3 . Interestingly, it has been found that, in $M$. ruber $\mathrm{M} 7$, in case of deletion, other enzyme(s) can carry out the same $\mathrm{C}-11$ reduction (15). The alcohol 3 is then oxidized by MrPigN (or MppF), a FADdependent monooxygenase, allowing the formation of the bicyclic pyranoquinone skeleton 4. On the other hand, MrPigJ ((or MpFasA2) a FAS subunit alpha) and MrPigK ((or MpFasB2) a FAS subunit beta) produce the side chain fatty acyl moiety of MonAzPs. The $\beta$-ketoacyl-ACP probably serves as the substrate for the AT MrPigD (or MppB) that directly transfers the fatty acyl chain to the $\mathrm{C}-4$ alcohol of (4) to produce the putative intermediate (5).

To produce the yellow pigments monasfluol A (7) and B (8), the pyranoquinone $\mathbf{5}$ is subjected to intramolecular Knoevenagel aldol condensations, leading to a tricyclic ring system $\mathbf{6}$ that is possibly reduced by $\mathrm{MrPigH}$ (or $\mathrm{MppE}$ ), an enoyl reductase.

The previously described pyranoquinone $\mathbf{5}$ could also undergo a two-step acetylation-elimination sequence successively catalyzed by MrPigM (or Mpp7), an $\mathrm{O}$-acetyltransferase, and MrPigO (or Mpp8), a deacetylase leading to the putative unsaturated intermediate 10. This latter may therefore go through two paths. One involves a regioselective Knoevenagel reaction, introducing the angular lactone, and a putative reduction by $\mathrm{MrPigH}$ to produce the yellow pigments monasfluore $A$ and $B$ (12 and $\mathbf{1 3}$ ).

The other path involves at first MrPigE (or MppC) a NAD(P)Hdependent oxidoreductase which reduces the $\mathrm{C} 4 \mathrm{a}(5)$ double bond of 10 followed by a regioselective Knoevenagel reaction, introducing the linear lactone and creating the tricyclic ring system 15. It should be noted that either linear or angular lactones could be obtained by Knoevenagel reaction, depending on the electronic nature of the $\pi$-conjugated system of the $4 \mathrm{H}$-pyran-4-ylidene moiety (8). In addition, it has also been reported that enzymatically controlled Knoevenagel reaction (Mpp7) could lead to the linear lactone whereas spontaneous condensation gave the angular one (14). Reduction of the furanone moiety of the linear tricyclic products may lead to the yellow pigments monascin (16) and ankaflavin (17) while its $\mathrm{C} 4 \mathrm{a}(5)$ double bond can be oxidized by MrPigF ((or MppG) a FAD-dependent oxidoreductase) to afford the orange pigments rubropunctatin (18) and monascorubrin (19). These two orange pigments can also lead to the formation of the red pigments rubropunctamine (20) and monascorubramine (21) by a direct reaction with endogenous ammonia or amino-acids (Figure 2).

The MAzPS cluster also contains several others genes like MrPigl (or MppR2) a transcription factor whose role in the biosynthesis pathway is unknown or MrPigB (or MppR1) a transcription factor known to control the expression of MrPigA, MrPigH, MrPigM, MrPigO, MrPigN and MrPigP (15). MrPigL (or Mpp15) is a ankyrin repeat protein but there is no functional verification so far (1). MrPigP (or Mppl) annotated as a MFS multidrug transporter was found not to be involved in the biosynthesis or the export of the Monascus azaphilones (15).

\section{The Aspergillus azaphilone pathway}

The biosynthetic pathway of azaphilones involving an hrPKS-nrPKS action in tandem was primarily found in the Aspergillus genus and has been described in Aspergillus nidulans (16), Chaetomium globosum (17), Ascomycete sp. F53(18), Aspergillus terreus (19) and Aspergillus niger ATCC 1015 (20).

The nrPKS and hrPKS can act in sequential, convergent, mixed or collaborative ways. In the sequential way, the first PKS forms a polyketide chain, which is later transferred to the second PKS to continue its elongation process. This case has been found in the asperfuranone biosynthesis (16). In the convergent way, the nrPKS and hrPKS can both function independently in parallel, and the two polyketide products are connected by accessory enzymes. This way is involved in the biosynthesis of azanigerone (20). In Chaetomium globosum, the caz biosynthetic cluster harbors a hrPKS acting both in a sequential and convergent manner with a nrPKS to produce the chaetoviridins or the chaetomugilin A. Finally, azasperpyranone is produced by a collaborative way involving two separate BGCs coordinated by transcriptional crosstalk (19). 


\section{ARTICLE}

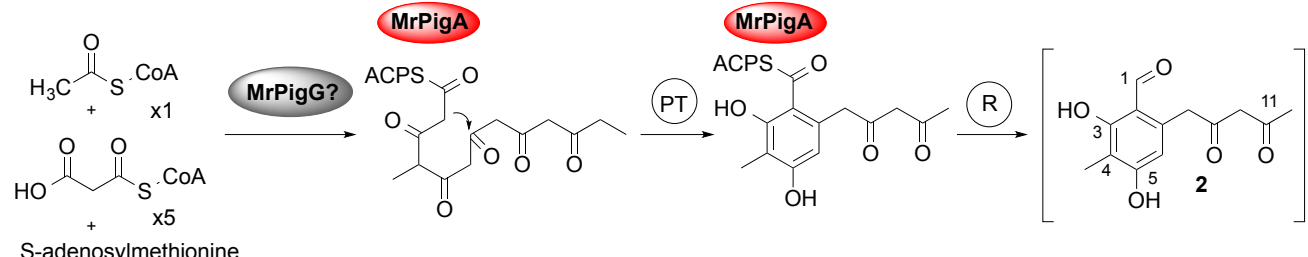

S-adenosylmethionine

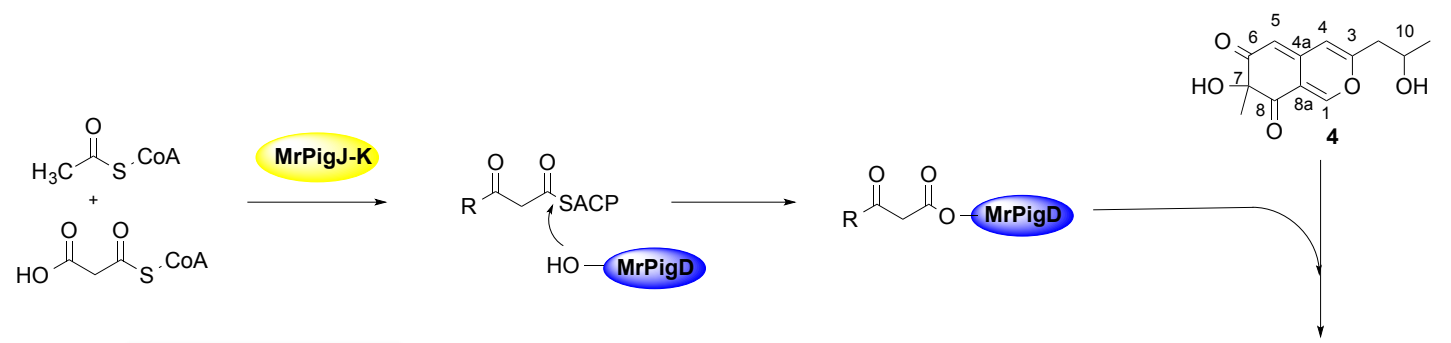

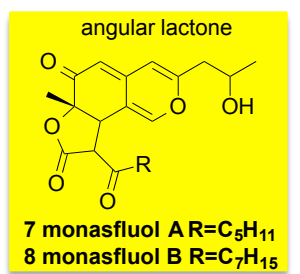

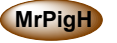

MrPigH
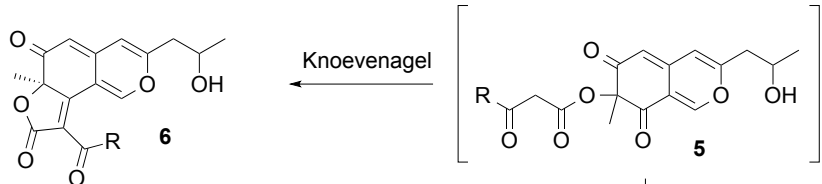
8 monastuol $B=C_{71}$

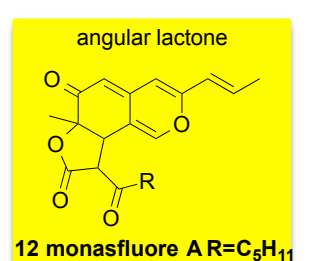
13 monasfluore $B R=C_{7} H_{15}$
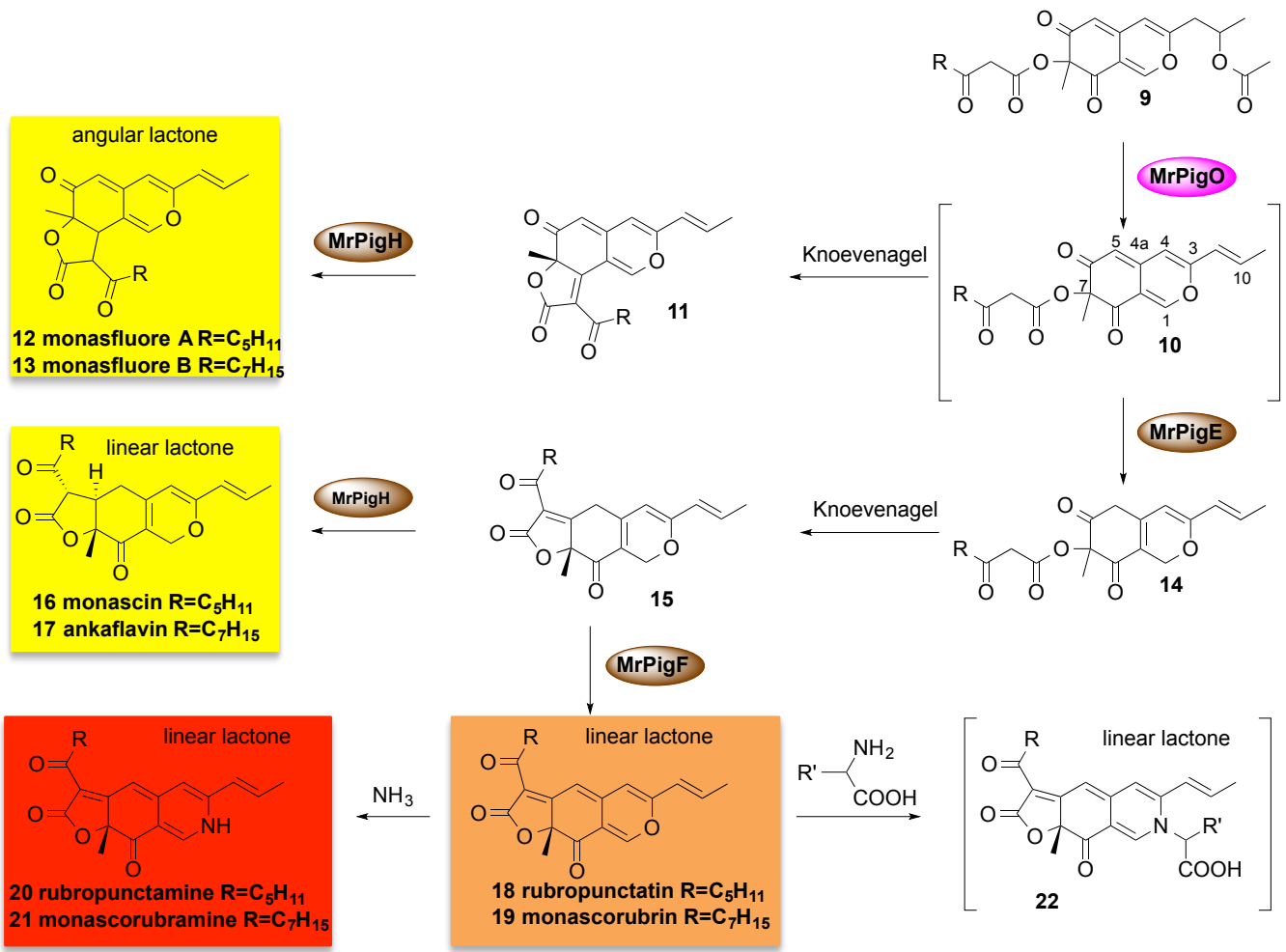

MrPigM

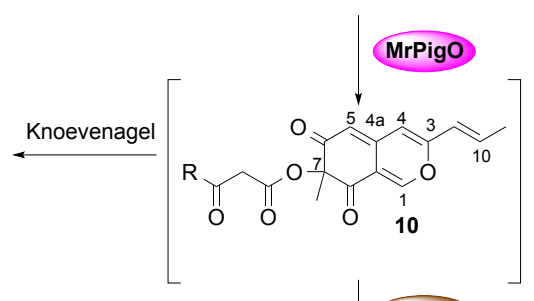

MrPigE

Knoevenagel<smiles>[R]C(=O)CC(=O)OC1(C)C(=O)CC2=C(C=C(C=CC)OC2)C1=O</smiles>

\section{MrPigF}
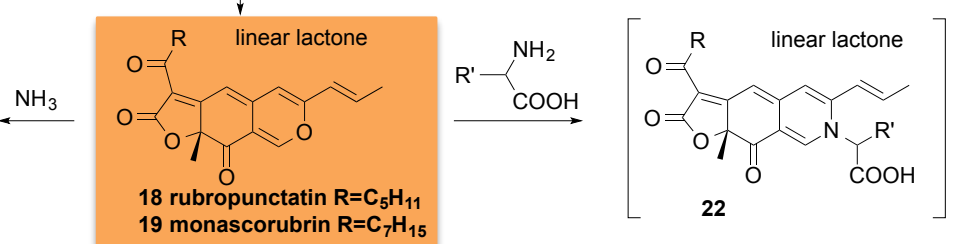

Figure 3 Proposed biosynthetic pathway for MonAzPs in M. ruber M7 (4) 


\section{ARTICLE}

\section{a. Sequential way}

Chiang et al. described in $A$. nidulans a cryptic gene cluster under normal laboratory growth conditions containing a nrPKS near a hrPKS (16). Closer examination of the gene cluster revealed that AfoA (coded by AN1029.3 gene) shares a high homology with CtnR, a citrinin biosynthesis transcriptional activator. By inducing the transcription activator located next to the two PKSs genes, Chiang et al. activated the PKS cryptic pathway involved in the asperfuranone biosynthesis. A series of gene deletion experiments allowed proposing the asperfuranone biosynthetic pathway that includes two PKSs (AfoE for the nrPKS and AfoG for the hrPKS) together with three additional proteinsAfoC, AfoF hydroxlating C-7 and AfoD hypothesized to hydroxylate C-7 which, in fact, hydroxylates C-3.$(21,22)$

Domain composition of AfoE was described as follow : SAT/KS/AT/PT/ACP/CMeT/R, when AfoG contained the domains: KS/AT/DH/CMeT/ER/KR/ACP.

Later, the putative asperfuranone gene cluster from $A$. terreus (ateafoA-G), highly homologous with the afoA-G gene cluster was cloned. By using $A$. nidulans heterologous expression system, they clarified the asperfuranone biosynthetic pathway (23).

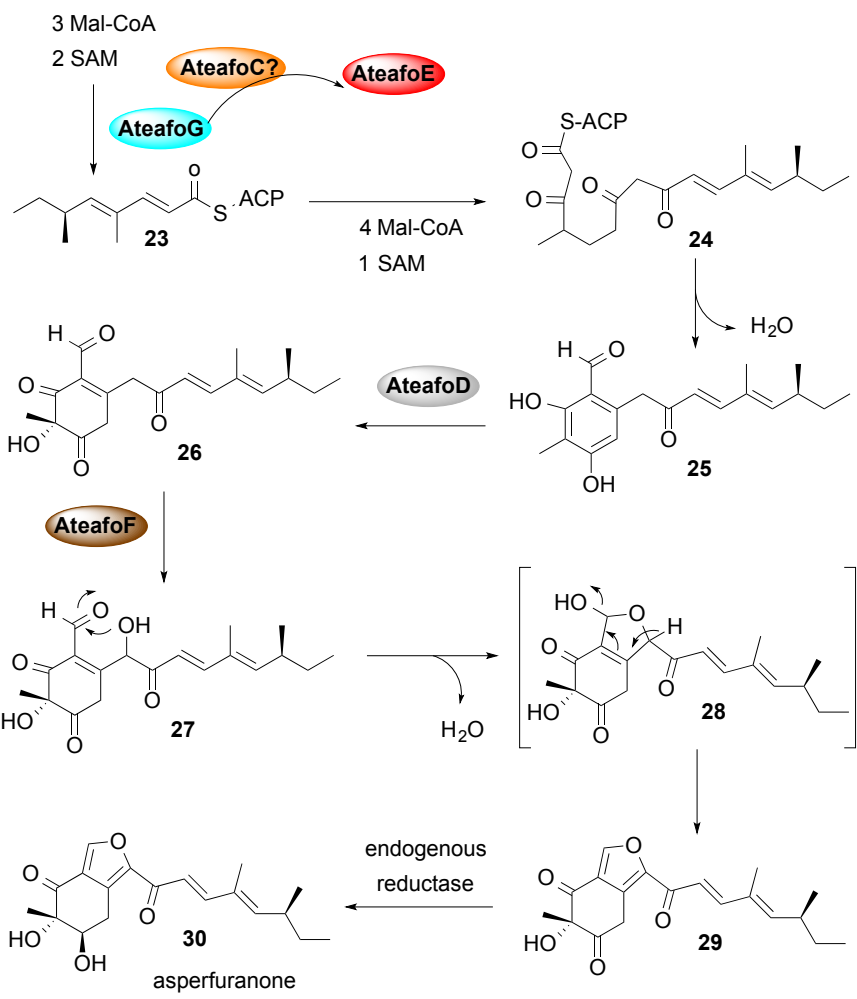

Figure 4 Proposed biosynthesis pathway for asperfuranone in $A$. nidulans $(16,21)$
The hrPKS AteafoG is responsible for the production of 3,5dimethyloctadienone, which is loaded onto the SAT domain of the nrPKS AteafoE for further extensions. Their results suggest that AteafoC might be involved in the releasing of $\mathbf{2 3}$ from AteAfoG or might facilitate the transfer from AteAfoG to AteAfoE. Then, the nrPKS AteAfoE uses four Malonyl-CoA and one SAM to produce the pentaone 24, which undergoes a cyclization to afford the aromatic ring 25. AteAfoD is proposed to have a dearomatization function of the precursor $\mathbf{2 5}$ to generate the hydroxylated intermediate $\mathbf{2 6}$. AteAfoF functions as a C-8 oxygenase to generate $\mathbf{2 7}$ which then undergoes spontaneous cyclization leading to compound $\mathbf{2 9}$ which is converted in asperfuranone (30) by an endogenous reductase (Figure 4).

\section{b. Convergent way}

In 2012, Zabala et al. found a similar cryptic gene cluster(20), using a convergent mode of collaboration for the hrPKS and nrPKS, on Aspergillus niger ATCC 1015 and compared it to the one previously found in Aspergillus nidulans (Figure 5).

aza

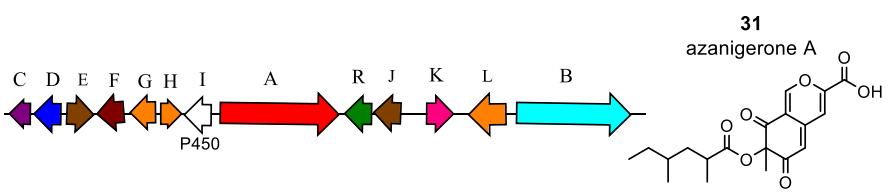

afo
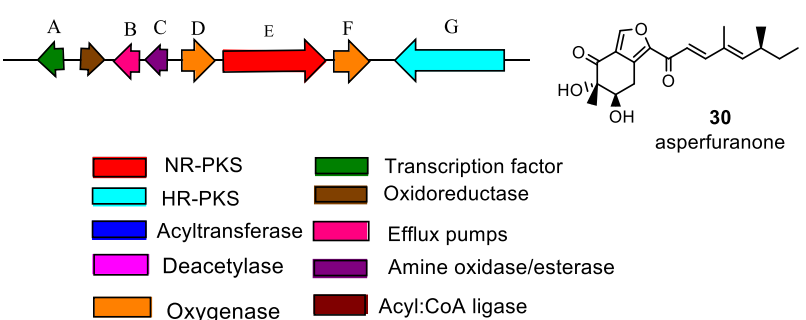

Figure 5 Comparison of the A. niger Aza cluster with the A. nidulans Afo cluster and their respective products. (20)

The biosynthetic pathway of asperfuranone (30) and azanigerone $A$ (31) share numerous homologs. Indeed, the AzaC, AzaG, AzaH, AzaJ and AzaL are tailoring enzymes (homologs of AfoC, AfoF, AfoD, AN1030 and AfoF respectively). It is noteworthy that function of AzaC remains enigmatic, the AzaB hrPKS (AfoG homolog) producing the dimethylhexanoate 38, the AzaA nrPKS (AfoE homolog) giving the aromatic compound 34, and the AzaR being a transcription factor (AfoA homolog). The main differences between asperfuranone and azanigerone pathways lie in the involvement for this latter of the AzaD acyltransferase in the transfer of the dimethylhexanoate $\mathbf{3 8}$ on the pyranoquinone $\mathbf{3 6}$ to produce the azaphilone 41, the AzaE ketoreductase which reduces the ketone 
function of $\mathbf{3 4}$ into hydroxyl, the AzaF AMP-dependent CoA ligase responsible of the ligation of $\mathbf{3 8}$ and the Azal cytochrome P450 which oxidizes the hydroxyl of $\mathbf{4 2}$ into an aldehyde (Figure 6). Interestingly, Zabala et al. found that AzaH, a key FAD-dependent monooxygenase encoded in the aza cluster had a role in the stereoselective $(24,25)$ hydroxylation at C-4 promoting thus the pyran-ring formation and leading to the characteristic bicyclic core of azaphilones (20).

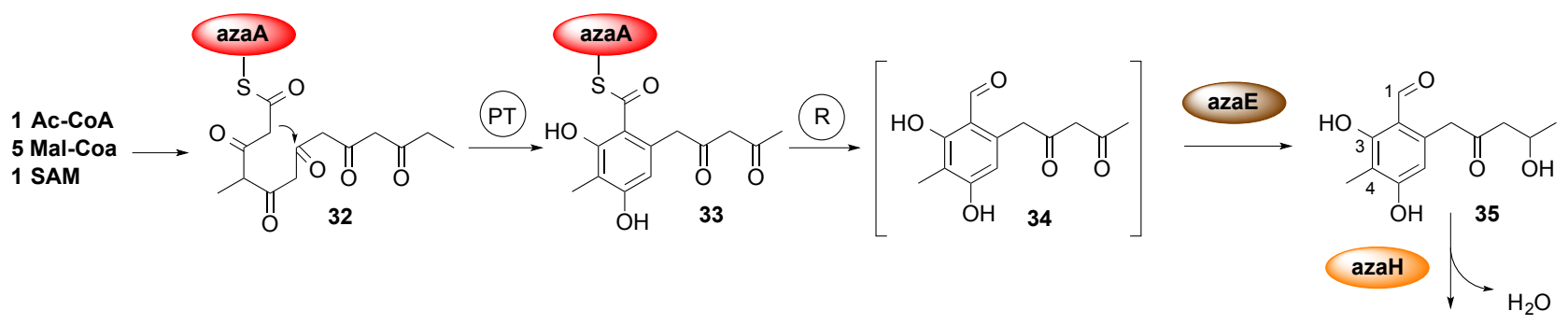

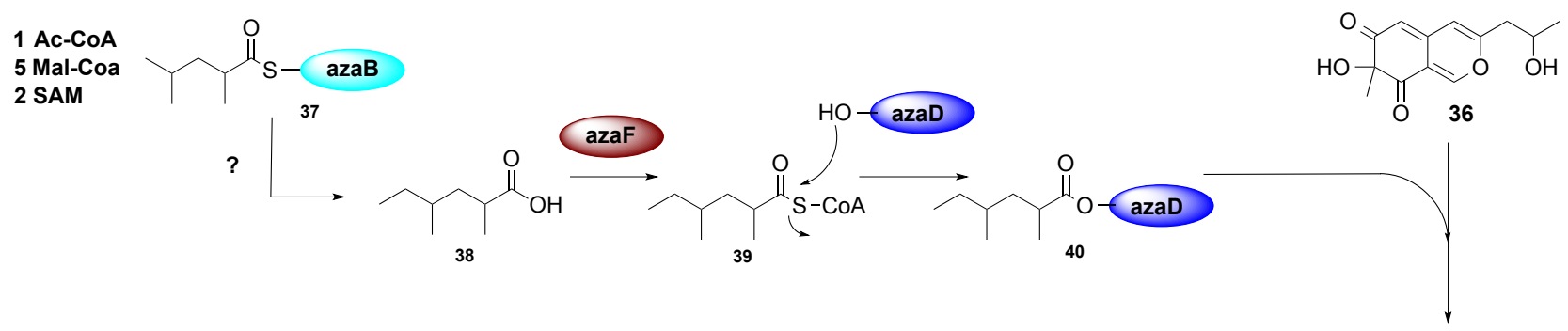<smiles></smiles><smiles>CCC(C)CC(C)C(=O)OC1(C)C(=O)C=C2C=C(C(=O)O)OC=C2C(=O)C1(C)C(C)C</smiles>

Figure 6 Proposed biosynthetic pathway for production of azanigerones. (20)

The aza pathway represented the first example of a convergent mode of collaboration between a hr- and a nrPKS, as opposed to the sequential mode of collaboration commonly observed in other dual PKS systems. Then, in March 2020, Jesse W. Cain et al. described the new azaphilone, lijiquinone, isolated from Ascomycete sp. F53 which is likely to be biosynthesized via a convergent pathway related to the one of Aspergillus (18).

\section{c. Sequential and convergent ways in Chaetomium globosum}

In Chaetomium globosum, the nrPKS (CazM) and the hrPKS (CazF) were described to act in both a sequential and convergent fashion (17) leading to chaetoviridin A (53) and chaetomugilin A (56).

The Caz biosynthetic gene cluster contains the CazM possessing domains described as follows : SAT/KS/MAT/PT/MT/ACP/R and the CazF possessing : KS/MAT/DH/MT/ER/KR/ACP $(17,26)$.

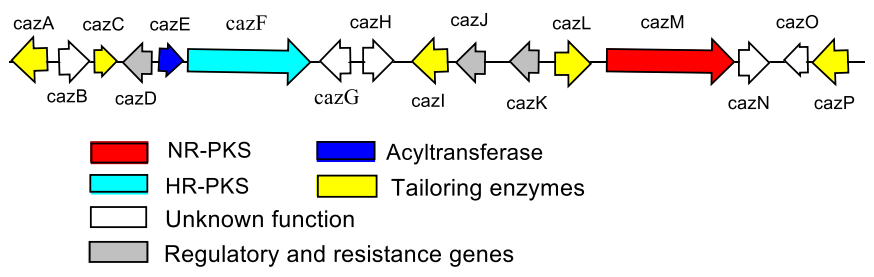

Figure 7 Caz biosynthetic gene cluster in C. globosum (17)

The hrPKS CazF most likely provides a highly reduced triketide $\mathbf{4 5}$ specifically selected by the SAT domain of the nrPKS CazM as start unit to produce the aromatic compound $\mathbf{4 7}$ in a collaborative mode of interaction between the two PKSs. This latter will be then processed by the halogenase Cazl followed by a hydroxylationcatalyzed annulation by the predictive monooyygenase CazL to afford the chloro-pyranoquinone named cazisochromene (49) (27). The additional oxidized triketide $\mathbf{5 0}$ produced by CazF is then added 
by the acyltransferase CazE to the pyranoquinone $\mathbf{4 9}$ giving the compound 52. The pyranoquinone $\mathbf{5 2}$ after Knoevenagel reaction leads to the tricyclic angular lactone 53, namely chaetoviridin A which relative side-chain configuration was revised recently (28).
Chaetoviridin A (53) then evolves to other chaetoviridins and chaetomugilins by rearrangements, reductions, oxidations or reaction with amines (Figure 8).

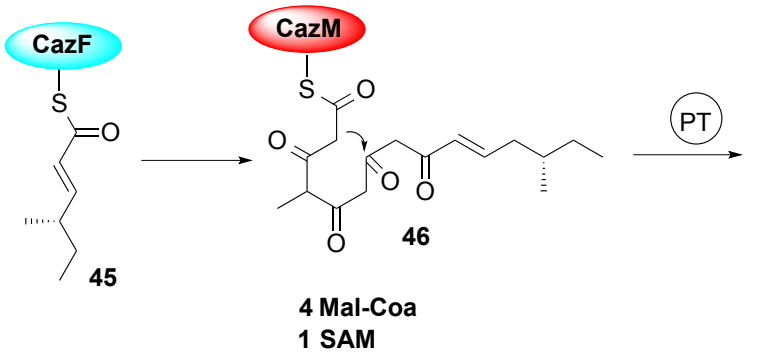

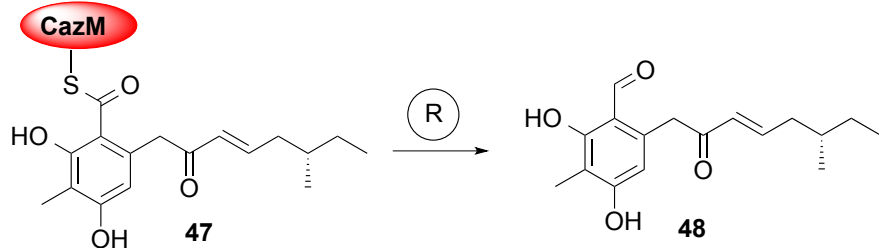

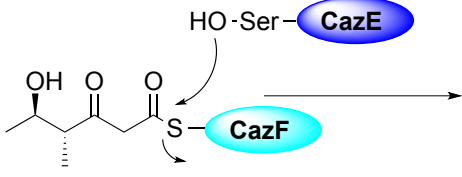

50<smiles>C[C@H](O)[C@H](C)C(=O)CC(=O)O[Se]c1ccccc1</smiles>

51<smiles>CC[C@H](C)/C=C/C1=CC2=C(Cl)C(=O)[C@]3(C)O[C@]4(O)[C@@H](C)[C@@H](C)OC(=O)[C@@H]4[C@H]3C2=CO1</smiles>

55

chaetoviridin B<smiles>[Tl]C1CCCCC1</smiles>

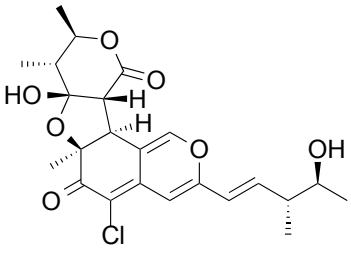

56

chaetomugilin A

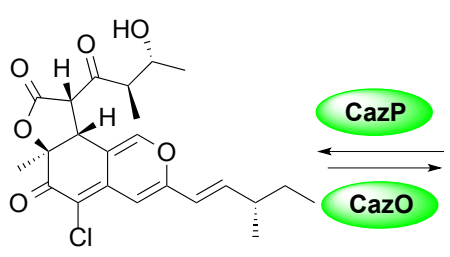

54

chaetoviridin $\mathbf{C}$

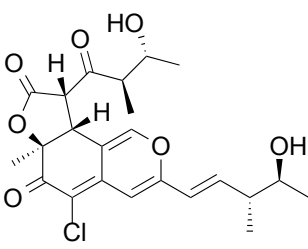

57

chaetomugilin M

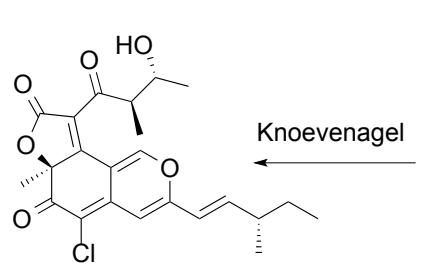

53<smiles>CCCCCCCC</smiles><smiles>CC[C@H](C)/C=C/C1=CC2=C(Cl)C(=O)[C@@](C)(O)C(=O)C2=CO1</smiles>

49

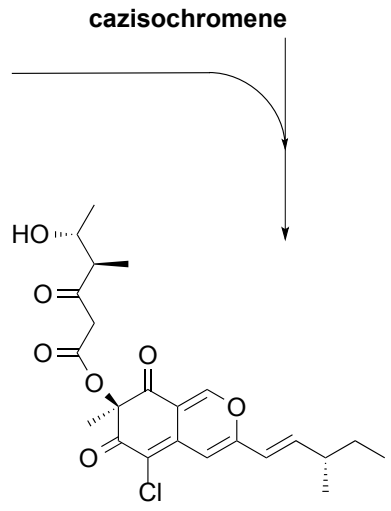

52

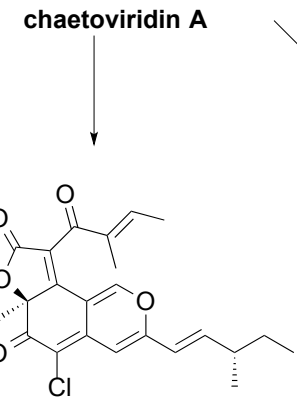

58

chaetoviridin E
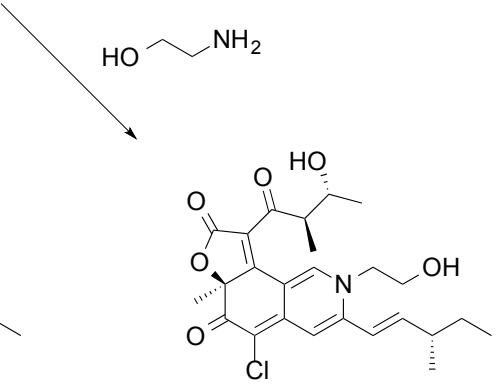

59

N-2-hydroxyethyl-chaetoviridin A

Figure 8 Proposed biosynthetic pathway of chaetoviridins and chaetomugilins $(17,23)$

\section{d. Collaborative biosynthesis}

In the matter of the mode of collaboration between polyketide synthases, Huang et al. provided further data in 2020 (19). Indeed transcriptome analysis of $A$. terreus showed that the production of the azaphilone azasperpyranone $A$ is correlated to the strongly cotranscription of two pairs of core megasynthase genes located at two separate BGCs which have been previously, separately characterized through heterologous expression, because both of them were silent in native $A$. terreus strains. Gene deletions and biochemical investigations demonstrated that the azaphilone azasperpyranone $A$ and derivatives were collaboratively synthetized by two separate clusters containing four core-enzymes, two nrPKSs, one hrPKS and one NRPS-like. The biosynthesis was found to be coordinately regulated by a transcriptional crosstalk between the two gene clusters involving three transcriptional factors. 
A
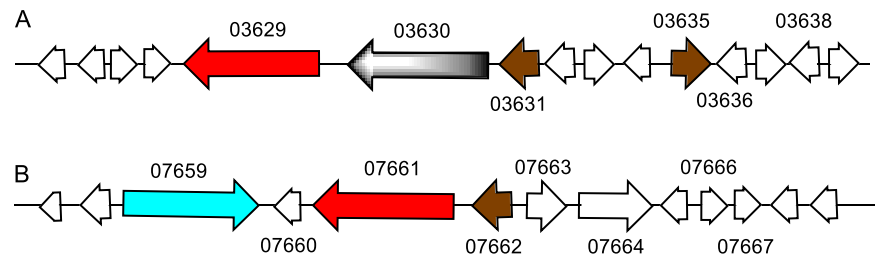

Figure 9 Genetic organization of the two BGCs (19)

The cluster A includes ATEG_03629 and ATEG_03630 encoding nrPKS and a NRPS-like respectively and is responsible of the polyhydric phenol moiety while cluster B includes ATEG_07659 and

ATEG_07661 encoding an hrPKS and a nrPKS, respectively led to the azaphilonoid scaffold 21 (see Figure 10).

Briefly, hrPKS ATEG_07659 gives a reduced polyketide elongated by the nrPKS ATEG_07661 and hydroxylated in C-4 by a FADdependent oxygenase ATEG_07662 to afford an aromatic ring intermediate leading to the the preasperpyranone (64). On the other hand, nrPKS ATEG_03629 produces orsellinic acid (67) which is then reduced by the NRPS-like ATEG_03630 leading to the benzaldehyde 69 . Hydroxylations are thus performed by ATEG_03635 and ATEG_03631 leading to the unstable compound 71 which most likely conducts to the stable lactone 73 . Enzymatic mechanisms involved in the covalent bond formation between the two scaffolds $\mathbf{6 4}$ and $\mathbf{7 1}$ leading to azasperpyranone A (74) still remain unknown.

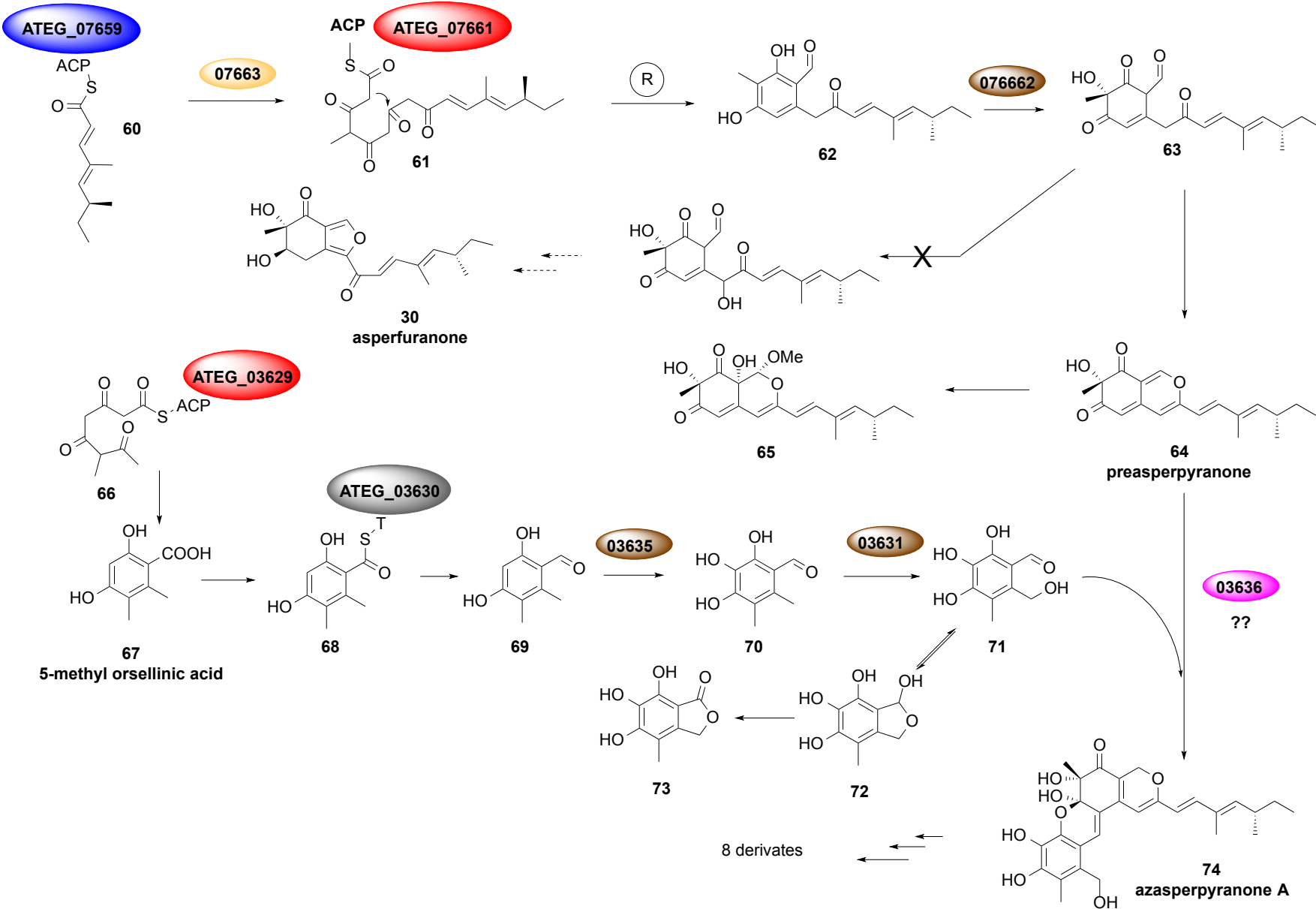

Figure 10 Proposed biosynthetic pathway of asperufranone and azasperpyranone A (19)

\section{The citrinin pathway}

Citrinin (85) is a polyketide-derived mycotoxin first isolated from Penicillium citrinum by Hetherington and Raistrick in 1931 and later from other Penicillium species as well as Aspergillus and Monascus species including Monascus ruber and Monascus purpureus $(29,30)$.
In 2015, little was still known of the individual chemical assembly steps of citrinin biosynthesis before $\mathrm{He}$ and Cox led the way, using targeted gene knockout and heterologous expression in Aspergillus oryzae with strong promoters to determine the steps of the citrinin biosynthesis in Monascus ruber M7 (30).

They found that the biosynthetic pathway involved CitS, a nrPKS with the domains SAT/KS/AT/PT/ACP/C-MeT/R, assisted by the hydrolase CitA, which was previously wrongly annotated as an 
oxidase, as well as oxidoreductases and hydrolases (named CitB, CitC, CitD, CitE; Figure 10). Briefly, they demonstrated that CitB is a non-heme iron oxidase, which oxidises the 12-methyl group of the keto-aldehyde $\mathbf{8 1}$ to benzyl-alcohol $\mathbf{8 2}$. They highlighted that subsequent steps are catalysed by $\mathrm{CitC}$, which oxidises the benzylic 12-hydroxyl to aldehyde 83 and CitD, which converts the 12benzaldehyde to the benzoic acid 84 . Final oxidation of $\mathrm{C}-3$ by CitE yields citrinin (85).

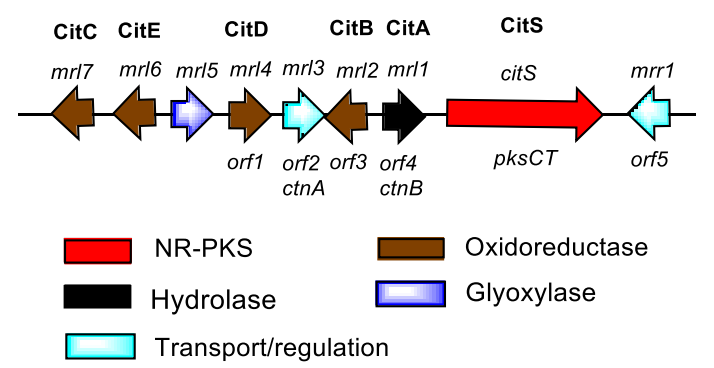

Figure 11 Proposed citrinin gene cluster from Monascus species (26)

Storm et al. in 2017 shed a new light on the nrPKS PksCT by domain deconstruction and reconstitution and demonstrated the role of $\mathrm{CMeT}$-catalyzed methylation in precursor elongation and pentaketide formation as represented in Figure 11. Indeed, methyl groups added by the CMeT would play the role of check-point tags that are recognized by KS domain (31).
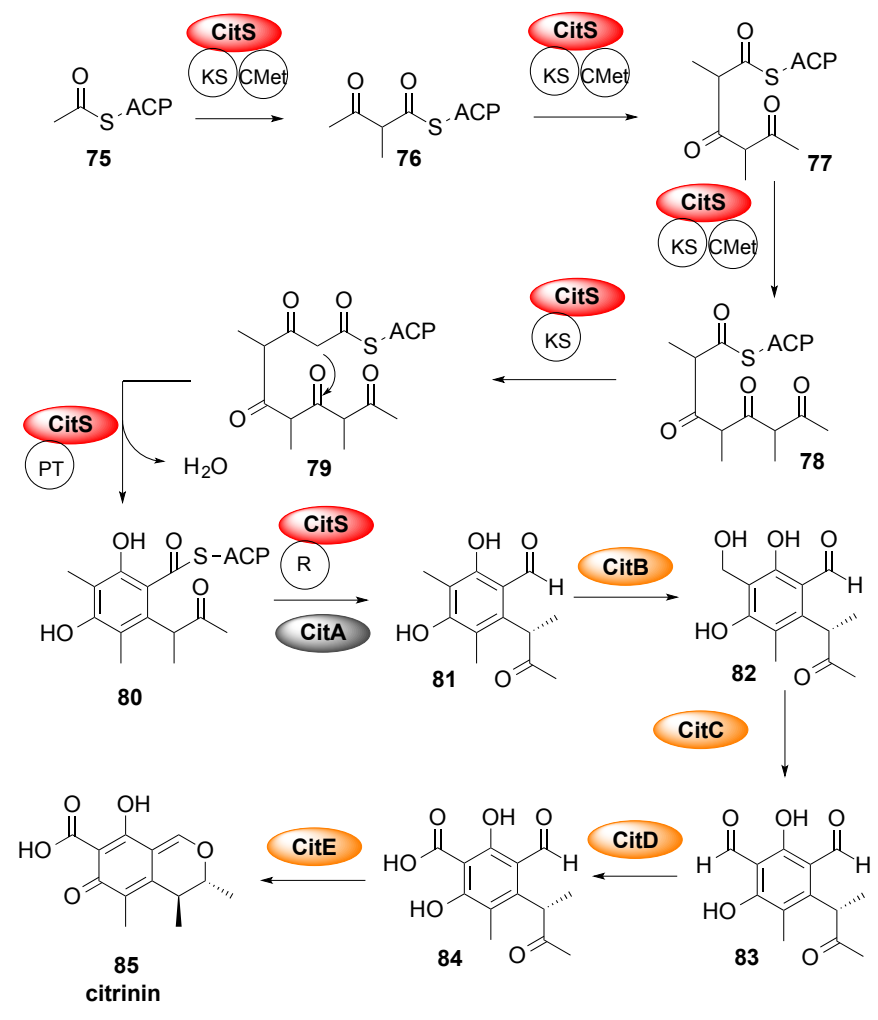

Figure 12 Proposed biosynthesis of citrinin $(26,28)$

\section{The Chaetomium/cochliodone pathway}

Few articles were published regarding the Chaetomium/cochliodone pathway. Yet, in 2013 Nakazawa et al. found the biosynthetic gene cluster of cochliodone $A$ and chaetoglobin A in Chaetomium globosum (Figure 13).
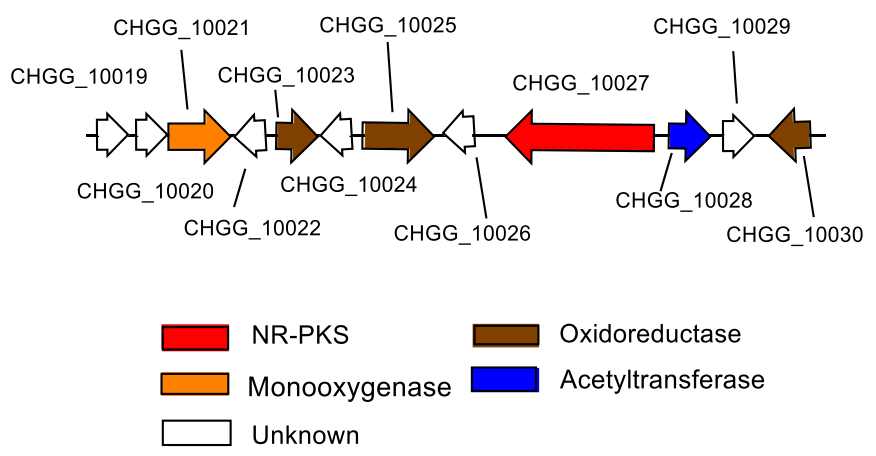

Figure 13 Proposed organization of cochliodones biosynthetic gene cluster in $C$. globosum (30)

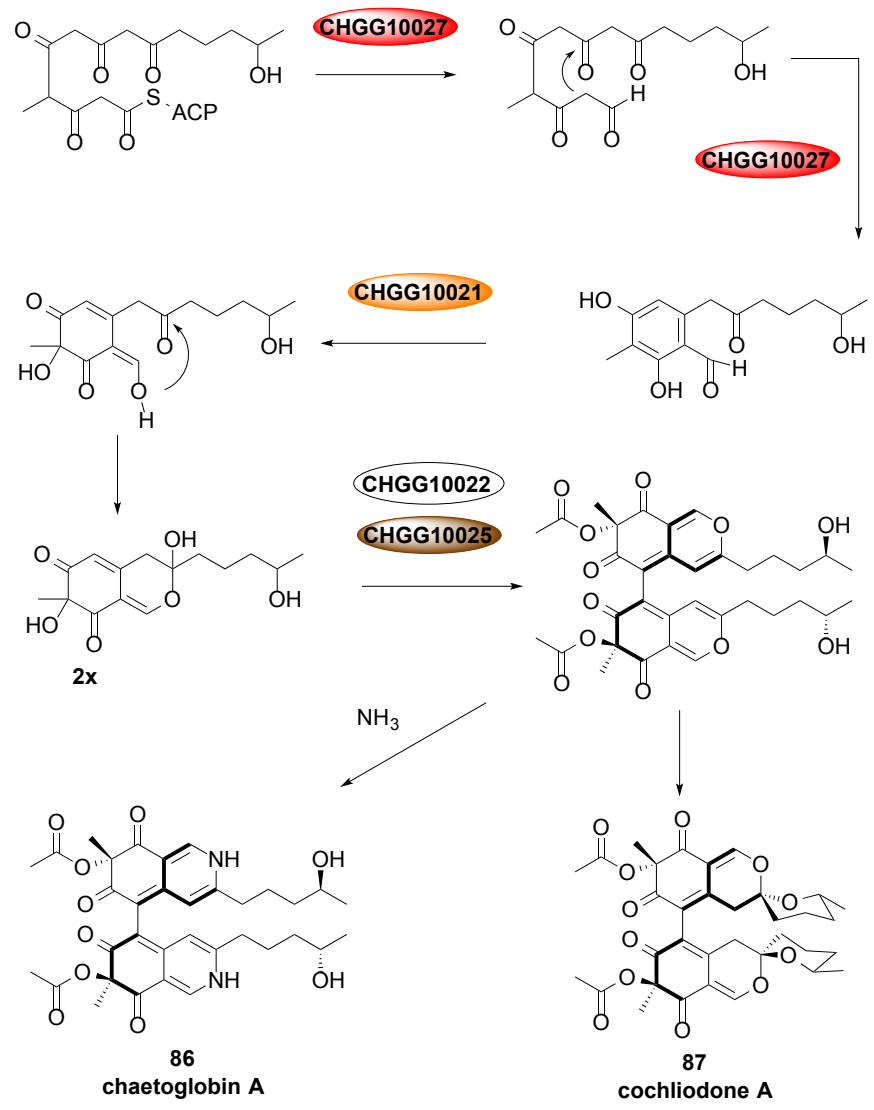

Figure 14 Proposed biosynthesis of cochliodone A and chaetoglobin A (30)

According to their similarity with other known genes and to knockout experiments, the gene CHGG_10027, a nrPKS, (later named CcdL) is thought to produce the polyketide core by accepting acetyl$\mathrm{COA}$ as a starting unit and four malonyl-CoA units which could then be transformed by CcdF (CHGG_10021, salicylate 1monooxygenase), CcdH (CHGG_10023, enoyl reductase), CcdM (CHGG_10028, acetyl transferase) and CcdO (CHGG_10030, enoyl reductase). The acetylation of the alcohol group on the ring system could be achieved by CcdM (CHGG_10028 presumed Oacetyltransferase). Finally, the fungal laccase like multi-copper oxidase encoded by CcdJ (CHGG_10025) is believed to dimerize the cochliodones $(32,33)$. 


\section{Hypoxylon pathway}

The Hypoxylon pathway was first reported from Penicillium marneffei, where two PKS genes pks12 and pks11 were described as probably responsible for mitorubrinol and mitorubrinic acid biosynthesis (34). Recently chemical investigation of the stromata of Hypoxylon fragiforme led to the isolation of unprecedented bisazaphilones motivating the examination of the $\mathrm{H}$. fragiforme genome to suggest their biosynthesis pathways.
By homology with known BGCs encoding azaphilones in Monascus ruber, azanigerones in Aspergillus niger and mitorubrinol in Talaromyces marneffei, two genes clusters among the seven nr-PKS present in $\mathrm{H}$. fragiforme were suggested as candidates for the biosynthesis of the isolated azaphilones. This cluster contains also two hydrolases, but no FAD-dependent monooxygenase, P450 monooxygenases, FAD-dependent oxidoreductases and transcription factors. Therefore, Becker et al. (35) propose that the two unlinked BGC, Hfaza1 and Hfaza2, act together in order to assemble and diversify azaphilones in $\mathrm{H}$. fragiforme.

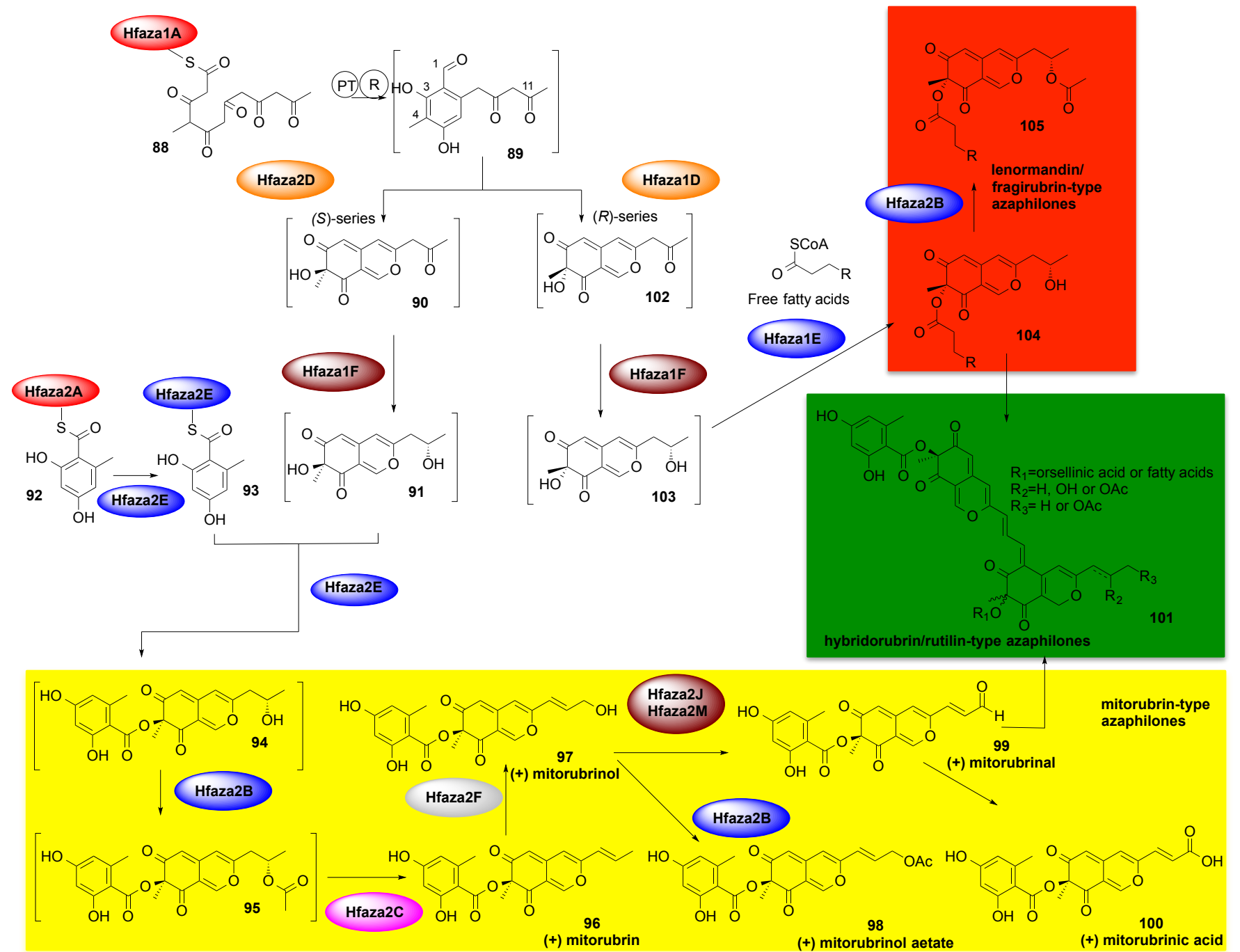

Figure 15 Biosynthetic hypothesis in $H$. fragiforme (31)

Indeed, the first BGC designated as hfaza1 contains the nr-PKS ( $\mathrm{Hfaza} 1 \mathrm{~A}$ ) producing a hexaketide chain $\mathbf{8 8}$ cyclized and reduced to produce the reactive benzaldehyde intermediate 89 . Also the FADdependent monooxygenases (Hfaza1D or Hfaza2D the latter from the BGC hfaza2) could hydroxylate 89 at C-4 follow by the subsequent spontaneous pyran ring formation of 102 . The BGC contains a ketoreductase (Hfaza1F) producing 103, which may thus undergo acylations by the acyltransferases Hfaza1E and Hfaza2B (from the second BGC) at the C-4 and C- 11 alcohols, respectively, to produce lenormandin/fragirubrin-type azaphilones. 104 could also dimerize to form the hybridorubrin/rutilin-type azaphilones (101). It is noteworthy that Hfaza1D and Hfaza2D encode a homologous enzyme suggesting they can perform the same reaction. This could therefore be consistent with the observation of different stereoconfigurations at C-4 between mitorubrin-type and fragirubrin-type azaphilones.

A second BGC designated as hfaza2 contains the nrR-PKS Hfaza2A (SAT-KS-AT-PT-ACP domains) biosynthesizing the orsellinic acid (92) added later at C-4 on to the pyranoquinone core by the acyltransferase Hfaza2E, homologous to Hfaza1E and MrPigD, and then acetylated by the putative acetyltransferase Hfaza2B. The deacetylase $\mathrm{Hfaza} 2 \mathrm{C}$ might then produce the pyranoquinone ring of mitorubrin (96), which would be then successively hydroxylated by 
a P450 monooxygenase (Hfaza2F) and oxidized by two FADdependent oxidoreductases (Hfaza2J and Hfaza2M) leading to the mitorubrin-type (96-100) or the hybridorubrin/rutilin-type azaphilones (101).

\section{Regulation of BGCs}

The growing interest towards the azaphilone family led to many attempts to regulate their biosynthetic pathways with the aim to improve their production. The regulation of secondary metabolism in fungi is complex and poorly understood. However, fungal gene clusters may be activated by several ways including epigenetic regulation, transcriptional regulation or stimuli, mimicking environmental stimuli, such as carbon and nitrogen sources, temperature, light, $\mathrm{pH}$, amino acids in the environment, reactive oxygen species, hypoxic conditions, biofilm formation and iron availability, but also stimuli derived from other organisms (36-38). It is noteworthy that BGCs activation is also dependent on the developmental stage of the producing fungus. With regard to azaphilone, some examples have been described.

The regulation of the MonAzPs pathway and/or the citrinin pathway have been the most studied given their importance in food and environmental toxicity, respectively. With the aim of enhancing the metabolic activity of polyketide pathways, several cultivation attempts have been performed such as carbon starvation stress leading to raise the acetyl-CoA pool (39) various light exposition (intensities and colors) (40-42), variation of carbon sources (43-45) or nitrogen $(3,44,46-51)$, different $\mathrm{pH}(44,52,53)$, cultivation in high-salt stress conditions (54) or at different temperatures (55). For instance, Guo et al. found that the Monascus pigments diversity is far more linked to transcriptional regulation than to DNA sequence variation (56). Jun Lv et al. discovered that the mycelial morphology was highly correlated to the Monascus yellow pigments yield, this was corroborated later on by Chen et al. $(53,54)$. Balakrishnan et al. found in 2016 that the reductase MrpigH (MppE) when overexpressed, promotes yellow pigment production whereas its inactivation enhanced orange and red pigment. Interestingly enough, Balakrishnan et al. highlighted also the fact that the overexpression of $\mathrm{MrPigH}$ enhancing the production of yellow pigments was dependent on culture method.(14)

In definitive, comparative transcriptome analysis reveals that several cultivation parameters may contribute to increase the azaphilone yield. Variation of nitrogen sources appear as one of the most important for MonAzPs, although it is important to keep in mind the specificity of the parameters for the considered strain.

With regard to the Aspergillus pathway, few studies were conducted on its regulation in particular because of the cryptic nature of the genes. Nevertheless it was found that the overexpression of the transcriptional regulator AzaR activates the aza cluster leading to the biosynthesis of several azanigerones not produced in the wild type strain (20). In the same way, the induced expression of the transcription factor gene afoA resulted in the expression of the entire $A$. nidulans asperfuranone cluster which is normally silent and to the production of asperfuranone (57).

In the collaborative way of the azasperpyranone biosynthesis, there might be a transcriptional crosstalk regulation between the two separate BGCs where ATEG_07667 regulated both of the cluster- specific regulators ATEG_03638 and ATEG_07666 allowing activation of their respective BGCs.

The Chaetomium/cochliodone pathway has been little studied so far. However, in C. globosum, deletion of laeA gene, and of the light-regulated developmental factor $\mathrm{VeA}$, leads to modulation of transcription of a number of biosynthetic gene clusters in $C$. globosum. Interestingly, in this strain, the polyketide aureonitol acts like a transcriptional regulator for the biosynthesis of chaetoviridins (33).

\section{Conclusion}

This work gives a general understanding on the described azaphilone biosynthetic pathways. Five biosynthetic pathways have been reported in the scientific literature, so far. The MazPs and Aspergillus pathways have been thoroughly studied unlike the citrinin and chaetomium pathways.

Better knowledge of the azaphilone biosynthesis pathway allowed to identify commons nrPKS and monooxygenases between the different pathways which may be used as specific probes for genome mining approach and that should pave the way towards the identification of promising azaphilones producers. An overall understanding of their biosynthesis pathways will also lay foundation for future genetic manipulation and engineering of the strains and should allow accelerating the discovery and the production of azaphilone lead.

\section{Conflicts of interest}

There are no conflicts to declare.

\section{Acknowledgements}

This work was partially supported by Normandie Université (NU), the Région Normandie, the Centre National de la Recherche Scientifique (CNRS) through the 80 Prime call and financial support to C.P., Université de Rouen Normandie (URN), INSA Rouen Normandie, Innovation Chimie Carnot (I2C) and Labex SynOrg (ANR-11-LABX-0029) through financial support to V.F.

\section{References}

1. Chen W, Feng Y, Molnár I, Chen F. Nature and nurture: confluence of pathway determinism with metabolic and chemical serendipity diversifies Monascus azaphilone pigments. Nat Prod Rep. 2019;36(4):561 72.

2. Chen C, Tao H, Chen W, Yang B, Zhou X, Luo X, Liu Y..Recent advances in the chemistry and biology of azaphilones. RSC Adv. 2020;10(17):10197 220. 
3. Hong J-L, Wu L, Lu J-Q, Zhou W-B, Cao Y-J, Lv W-L, Liu B, Rao $\mathrm{P}-\mathrm{F}, \mathrm{Lv} \mathrm{X}-\mathrm{C}$. Comparative transcriptomic analysis reveals the regulatory effects of inorganic nitrogen on the biosynthesis of Monascus pigments and citrinin. RSC Adv. 2020;10(9):5268 82

4. Chen W, Chen R, Liu Q, He Y, He K, Ding X, Kang L, Guo X, Xie N, Zhou Y, Lu Y, Cox RJ, Molnár I, Li M, Shao Y, Chen F. Orange, red, yellow: biosynthesis of azaphilone pigments in Monascus fungi Chem Sci. 2017;8(7):4917 25.

5. Balakrishnan B, Karki S, Chiu S-H, Kim H-J, Suh J-W, Nam B, Yoon Y-M, Chen C-C, Kwon H-J. Genetic localization and in vivo characterization of a Monascus azaphilone pigment biosynthetic gene cluster. Appl Microbiol Biotechnol. 2013;97(14):6337 45.

6. Xie N, Liu Q, Chen F. Deletion of pigR gene in Monascus ruber leads to loss of pigment production. Biotechnol Lett. 2013;35(9):1425 32.

7. Xie NN, Zhang YP, Chen FS. Identification of a pigmentpolyketide synthase gene deleted mutant of Monascus ruber M7. Wei Sheng Wu Xue Bao. 2015;55(7):863 72.

8. Bijinu B, Suh J-W, Park S-H, Kwon H-J. Delineating Monascus azaphilone pigment biosynthesis: oxidoreductive modifications determine the ring cyclization pattern in azaphilone biosynthesis. RSC Adv. 2014;4(103):59405 8.

9. Liu Q, Xie N, He Y, Wang L, Shao Y, Zhao H, Chen F. MpigE, a gene involved in pigment biosynthesis in Monascus ruber M7. Appl Microbiol Biotechnol. 2014;98(1):285 96.

10. Balakrishnan B, Park S-H, Kwon H-J. Inactivation of the oxidase gene mppG results in the selective loss of orange azaphilone pigments in Monascus purpureus. Appl Biol Chem. 2017;60(4):437 46.

11. Balakrishnan B, Chandran R, Park S-H, Kwon H-J. A New Protein Factor in the Product Formation of Non-Reducing Fungal Polyketide Synthase with a C-Terminus Reductive Domain. J Microbiol Biotechnol. 2015;25(10):1648 52.

12. Balakrishnan B, Park S-H, Kwon H-J. A reductase gene mppE controls yellow component production in azaphilone polyketide pathway of Monascus. Biotechnol Lett. 2017;39(1):163 9.

13. Balakrishnan B, Kim H, Suh J-W, Chen C-C, Liu K-H, Park SH, Kwon HJ. Monascus azaphilone pigment biosynthesis employs a dedicated fatty acid synthase for short chain fatty acyl moieties. J Korean Soc Appl Biol Chem. 2014; 57: 191196.

14. Balakrishnan B, Chen C-C, Pan T-M, Kwon H-J. Mpp7 controls regioselective Knoevenagel condensation during the biosynthesis of Monascus azaphilone pigments. Tetrahedron Lett. 2014;55(9):1640 3.
15. Li M, Kang L, Ding X, Liu J, Liu Q, Shao Y, Molnár I, Chen F. Monasone naphthoquinone biosynthesis and resistance in Monascus fungi. mBio 2020, 11 (1) e02676-19

16. Chiang Y-M, Szewczyk E, Davidson AD, Keller N, Oakley BR, Wang CCC. A gene cluster containing two fungal polyketide synthases encodes the biosynthetic pathway for a polyketide, asperfuranone, in Aspergillus nidulans. J Am Chem Soc. 2009;131(8):2965 70.

17. Winter JM, Sato M, Sugimoto S, Chiou G, Garg NK, Tang $Y$, Watanabe K. Identification and characterization of the chaetoviridin and chaetomugilin gene cluster in Chaetomium globosum reveals dual functions of an iterative highlyreducing polyketide synthase. J Am Chem Soc. 2012;134(43):17900 3 .

18. Cain JW, Miller KI, Kalaitzis JA, Chau R, Neilan BA. Genome mining of a fungal endophyte of Taxus yunnanensis (Chinese yew) leads to the discovery of a novel azaphilone polyketide, lijiquinone. Microb Biotechnol. 2020; 13:1415-1427.

19. Huang X, Zhang W, Tang S, Wei S, Lu X. Collaborative biosynthesis of a class of bioactive azaphilones by two separate gene clusters containing four PKS/NRPSs with transcriptional crosstalk in fungi. Angew Chem Int Ed. 2020;59(11):4349 53.

20. Zabala AO, Xu W, Chooi Y-H, Tang Y. Characterization of a silent azaphilone gene cluster from Aspergillus niger ATCC 1015 reveals a hydroxylation-mediated pyran-ring formation. Chem Biol. 2012;19(8):1049 59.

21. Davison J, Fahad A al, Cai M, Song Z, Yehia SY, Lazarus CM, Bailey AM, Simpson TJ, Cox RJ Genetic, molecular, and biochemical basis of fungal tropolone biosynthesis. Proc Natl Acad Sci. 2012;109(20):7642 7.

22. Zabala AO, Xu W, Chooi Y-H, Tang Y. Discovery and characterization of a silent gene cluster that produces azaphilones from Aspergillus niger ATCC 1015 reveal a hydroxylation-mediated pyran-ring formation. Chem Biol. 2012;19(8):1049 59.

23. Chiang Y-M, Oakley CE, Ahuja M, Entwistle R, Schultz A, Chang S-L, Sung CT, wang CCC, Oakley BR. An efficient system for heterologous expression of secondary metabolite genes in Aspergillus nidulans. J Am Chem Soc. 2013;135(20):7720 31.

24. Pyser JB, Baker Dockrey SA, Benítez AR, Joyce LA, Wiscons RA, Smith JL, Narayan ARH. Stereodivergent, chemoenzymatic synthesis of Azaphilone natural products. J Am Chem Soc. 2019;141(46):18551 9.

25. Baker Dockrey SA, Lukowski AL, Becker MR, Narayan $\mathrm{ARH}$. Biocatalytic site- and enantioselective oxidative dearomatization of phenols. Nat Chem. 2018;10(2):119 25. 
26. Winter JM, Cascio D, Dietrich D, Sato M, Watanabe K, Sawaya MR, Vederas JC, Tang Y. Biochemical and structural basis for controlling chemical modularity in fungal polyketide biosynthesis. J Am Chem Soc. 2015;137(31):9885 93.

27. Sato $M$, Winter JM, Kishimoto $S$, Noguchi $H$, Tang $Y$, Watanabe K. Combinatorial generation of chemical diversity by redox rnzymes in Chaetoviridin biosynthesis. Org Lett. 2016;18(6):1446 9.

28. Makrerougras M, Coffinier R, Oger S, Chevalier A, Sabot $C$, Franck $X$. Total synthesis and structural revision of Chaetoviridins A. Org Lett. 2017;19(15):4146 9.

29. Gore TS, Panse TB, Venkataraman K. Citrinin. Nature. 1946;157(3985):333 333.

30. He Y, Cox RJ. The molecular steps of citrinin biosynthesis in fungi. Chem Sci. 2016;7(3):2119 27.

31. Storm PA, Herbst DA, Maier T, Townsend CA. Functional and structural analysis of programmed C-methylation in the biosynthesis of the fungal polyketide Citrinin. Cell Chem Biol. 2017;24(3):316 25.

32. Sarmales-Murga C, Akaoka F, Sato M, Takanishi J, Mino $\mathrm{T}$, Miyoshi N, Watanabe K. A new class of dimeric product isolated from the fungus Chaetomium globosum: evaluation of chemical structure and biological activity. J Antibiot (Tokyo). 2020;73(5):320 3.

33. Nakazawa $T$, Ishiuchi $K$, Sato $M$, Tsunematsu $Y$, Sugimoto $S$, Gotanda Y, Nogushi H, Hotta K, Watanabe K. Targeted disruption of transcriptional regulators in Chaetomium globosum activates biosynthetic pathways and reveals transcriptional regulator-Like behavior of aureonitol. J Am Chem Soc. 2013;135(36):13446 55.

34. Woo PCY, Lam C-W, Tam EWT, Leung CKF, Wong SSY, Lau SKP, Yuen K-Y. First discovery of two polyketide synthase genes for mitorubrinic acid and mitorubrinol yellow pigment biosynthesis and implications in virulence of Penicillium marneffei. PLoS NegI Trop Dis. 6(10): e1871 2012.doi.org/10.1371/journal.pntd.0001871

35. Becker K, Pfütze S, Kuhnert E, Cox R, Stadler M, Surup F. Hybridorubrins A-D, novel azaphilone heterodimers from stromata of Hypoxylon fragiforme and insights into the biosynthetic machinery for azaphilone diversification. Chemistry. 2020; 10.1002/chem.202003215.

36. Brakhage AA. Regulation of fungal secondary metabolism. Nat Rev Microbiol. 2013;11(1):21 32.

37. Hautbergue T, Jamin EL, Debrauwer L, Puel O, Oswald IP. From genomics to metabolomics, moving toward an integrated strategy for the discovery of fungal secondary metabolites. Nat Prod Rep. 2018;35(2):147 73.

38. Wiemann P, Lechner BE, Baccile JA, Velk TA, Yin W-B, Bok JW, Pakala S, losada L, Nierman WC, Schroeder FC, Haas H,
Keller NP. Perturbations in small molecule synthesis uncovers an iron-responsive secondary metabolite network in Aspergillus fumigatus. Front Microbiol. 2020; 5:530

39. Yang Y, Liu B, Du X, Li P, Liang B, Cheng X, Du L, Huang D, Wang $L$, Wang $S$. Complete genome sequence and transcriptomics analyses reveal pigment biosynthesis and regulatory mechanisms in an industrial strain, Monascus purpureus YY-1. Sci Rep. 2015;5:8331. .

40. Chen D, Xue C, Chen M, Wu S, Li Z, Wang C. Effects of blue light on pigment biosynthesis of Monascus. J Microbiol Seoul Korea. 2016;54(4):305 10.

41. Wang L, Dai Y, Chen W, Shao Y, Chen F. Effects of Light Intensity and color on the biomass, extracellular red pigment, and Citrinin production of Monascus ruber. J Agric Food Chem. 2016;64(50):9506 14.

42. Wang C, Chen D, Chen M, Wang Y, Li Z, Li F. Stimulatory effects of blue light on the growth, monascin and ankaflavin production in Monascus. Biotechnol Lett. 2015;37(5):1043 8 .

43. Embaby AM, Hussein MN, Hussein A. Monascus orange and red pigments production by Monascus purpureus ATCC16436 through co-solid state fermentation of corn cob and glycerol: An eco-friendly environmental low cost approach. PLOS ONE.2018;13(12):e0207755.

44. Lin TF, Demain AL. Effect of nutrition of Monascus sp. on formation of red pigments. Appl Microbiol Biotechnol. 1991;36(1):70 5 .

45. Huang Z-R, Zhou W-B, Yang X-L, Tong A-J, Hong J-L, Guo W-L, Li T-L, Jia R-B, Pan Y-Y, Lin J, Lv X-C, Liu B.The regulation mechanisms of soluble starch and glycerol for production of azaphilone pigments in Monascus purpureus FAFU618 as revealed by comparative proteomic and transcriptional analyses. Food Res Int Ott Ont. 2018;106:626 35.

46. Arai T, Umemura S, Ota T, Ogihara J, Kato J, Kasumi T. Effects of inorganic nitrogen sources on the production of PP-V [(10Z)-12-carboxyl-monascorubramine] and the Expression of the nitrate assimilation gene cluster by Penicillium sp. AZ. Biosci Biotechnol Biochem. 2012;76(1):120 4 .

47. Lešová K, Šturdíková M, Rosenberg M. Factors affecting the production of (-)-mitorubrinic acid by Penicillium funiculosum. J Basic Microbiol. 2000;40(5 6):369 75.

48. Kang B, Zhang X, Wu Z, Wang Z, Park S. Production of citrinin-free Monascus pigments by submerged culture at low pH. Enzyme Microb Technol. 2014;55:50 7.

49. Arai T, Koganei K, Umemura S, Kojima R, Kato J, Kasumi $\mathrm{T}$, Ogihara J. Importance of the ammonia assimilation by Penicillium purpurogenum in amino derivative Monascus pigment, PP-V, production. AMB Express. 2013;3(1):19. 
50. Lin TF, Demain AL. Negative effect of ammonium nitrate as nitrogen source on the production of water-soluble red pigments by Monascus sp. Appl Microbiol Biotechnol. 1995;43(4):701 5.

51. Zhou B, Ma Y, Tian Y, Li J, Zhong H. Quantitative Proteomics analysis by sequential window acquisition of all theoretical mass spectra-mass spectrometry reveals inhibition mechanism of pigments and Citrinin production of Monascus response to high ammonium chloride concentration. J Agric Food Chem. 2020;68(3):808 17.

52. Chen $\mathrm{M}-\mathrm{H}$, Johns MR. Effect of $\mathrm{pH}$ and nitrogen source on pigment production by Monascus purpureus. Appl Microbiol Biotechnol.1993;40(1):132 8.

53. Lv J, Zhang B-B, Liu X-D, Zhang C, Chen L, Xu G-R, Cheng $P C K$. Enhanced production of natural yellow pigments from Monascus purpureus by liquid culture: The relationship between fermentation conditions and mycelial morphology. J Biosci Bioeng. 2017;124(4):452 8.

54. Chen G, Yang S, Wang C, Shi K, Zhao X, Wu Z. Investigation of the mycelial morphology of Monascus and the expression of pigment biosynthetic genes in high-salt-stress fermentation. Appl Microbiol Biotechnol. 2020;104(6):2469 79.

55. Huang T, Tan H, Chen G, Wang L, Wu Z. Rising temperature stimulates the biosynthesis of watersoluble fluorescent yellow pigments and gene expression in Monascus ruber CGMCC10910. AMB Express. 2017;7(1):134

56. Guo X, Li Y, Zhang R, Yu J, Ma X, Chen M, Wang Y. Transcriptional regulation contributes more to Monascus pigments diversity in different strains than to DNA sequence variation. World J Microbiol Biotechnol. 2019;35(9):138 138. 